\title{
ESCOLA 100\% RECICLÁVEL: EDUCAÇÃO AMBIENTAL FORMAL NAS UNIDADES ESCOLARES MUNICIPAIS DE PINHAIS (PR)
}

\author{
Nirma Nemitz ${ }^{1}$ \\ Liliane Azeredo Dias ${ }^{2}$ \\ Juliana Zanetti Ribeiro ${ }^{3}$
}

Resumo: O projeto Escola 100\% Reciclável iniciou-se em 2014 com o objetivo de sensibilizar e conscientizar alunos e funcionários sobre a importância do meio ambiente, centrado na metodologia dos 5R's: Recusar, Repensar, Reduzir, Reutilizar e Reciclar. Ocorre por adesão, sendo realizado o diagnóstico, palestra, atividades lúdicas e monitoramento. Foi implantado em 23 unidades escolares, totalizando 281 turmas, 7316 alunos e 979 funcionários. Dos resultados é possível apontar que é por meio de posturas pedagógicas comprometidas que se pode mudar atitudes e construir novos hábitos. É justamente a disseminação, a reflexão e a construção do conhecimento sobre práticas ambientais corretas que movem a Educação Ambiental.

Palavras Chave: Meio Ambiente; Educação Ambiental; Conscientização Ambiental.

Abstract: The 100\% Recyclable School project started in 2014 with the objective of sensitizing and making students and employees aware of the importance of the environment, centered on the 5R's methodology: Refuse, Rethink, Reduce, Reuse and Recycle. It occurs through adherence, with diagnosis, lecture, play activities and monitoring. It was implemented in 23 school units, totaling 281 classes, 7316 students and 979 employees. From the results it is possible to point out that it is through compromised pedagogical attitudes can be changed and new habits can be built. It is precisely the dissemination, reflection and construction of knowledge about correct environmental practices that drive Environmental Education.

Keywords: Environment; Environmental Education; Environmental Awareness.

${ }^{1}$ Prefeitura Municipal de Pinhais. E-mail: nirma.nemitz@pinhais.pr.gov.br.

2 Prefeitura Municipal de Pinhais. E-mail: liliane.dias@pinhais.pr.gov.br.

${ }^{3}$ Prefeitura Municipal de Pinhais. E-mail: juliana.zanetti@pinhais.pr.gov.br. 


\section{Introdução}

O termo Educação Ambiental (EA) surgiu na década de 1960 na GrãBretanha, sendo inserida a partir daí nas discussões mundiais, levantando a questão sobre qual sociedade presente e futura desejamos.

No Brasil a escola ainda é o centro do desenvolvimento da EA, não por ser a única responsável, mas sim por trabalhar com uma prática pedagógica planejada e sistemática, de forma contínua e integrada podendo funcionar de forma transversal no desenvolvimento de pessoas com uma consciência ambiental mais adequada ao mundo atual (CONAE/PR, 2015).

A prática da EA, seja ela formal ou não, deve buscar a formação de cidadãos de forma contínua e em toda a sua vida, buscando sempre despertar nos envolvidos a melhoria da qualidade de vida. A sustentabilidade ambiental depende das ações de todos, e não se faz somente com discurso ou ações pontuais, mas sim na mudança real da forma de pensar que se reflete em ações cotidianas para melhoria ambiental (CAVALCANTI, 2002).

Diante disso, em 2014 no município de Pinhais/Pr, foi dado início a um projeto que busca sensibilizar e conscientizar a comunidade escolar de forma direta (alunos, professores e funcionários) e indireta (pais e comunidade local) sobre a importância de cada indivíduo e de suas ações cotidianas na melhoria do meio ambiente, transformando-os em multiplicadores de ações ambientais positivas

\section{Metodologia}

O município de Pinhais possui 44 unidades escolares, com cerca de 13.710 alunos, 557 turmas, 482 educadores infantis, 624 professores, 103 pedagogos, 3 pedagogos de Educação Especial e 128 servidores em geral.

O projeto ocorre por adesão voluntária das unidades escolares e, por ordem dessa inscrição a implantação é realizada. Tem como princípio abordar a conscientização do descarte correto de materiais, a redução do desperdício de alimentos e a valorização da biodiversidade, com o paisagismo e a horta. Para a conscientização do descarte correto dos materiais são realizadas, primeiramente o diagnóstico da unidade, seguido de palestras e atividades lúdicas com todos os envolvidos no processo. As palestras sensibilizam sobre a importância do meio ambiente, sempre pautado na metodologia dos $5 R$ 's da EA: Recusar, Repensar, Reduzir, Reutilizar e Reciclar. As atividades lúdicas buscam motivá-los, de acordo com a faixa etária a ser trabalhada, a serem protagonistas de suas histórias e agentes transformadores do meio em que estão inseridos. Nas salas de aula e áreas comuns são colocadas lixeiras para - descarte de resíduos orgânicos e recicláveis, que são vistoriadas frequentemente como forma de monitoramento e se for necessário ocorre nova re-estimulação dos conceitos e práticas sustentáveis seguindo a ordem 
crescente na escala das categorias, indo da sensibilização até a Cidadania Ambiental como preconiza Smyth (1995).

A redução do desperdício de alimentos é trabalhada de forma diferenciada entre os funcionários e alunos, sempre em parceria com as nutricionistas responsáveis. Com os funcionários são trabalhados a quantidade adequada de alimentos a ser preparada, conforme o número de alunos presentes no dia e a porção adequada de alimento a ser servida. Junto aos alunos são trabalhados os impactos ambientais da produção de alimentos e desperdício dos mesmos.

Já na valorização da biodiversidade, busca-se com o paisagismo despertar nos alunos e funcionários a importância das plantas para a redução da temperatura, o bem-estar visual, redução de ruídos e da poluição. Na horta, o envolvimento de alunos se dá desde o plantio, passando pela colheita e consumo dos produtos, estimulando o contato com a terra e as plantas, buscando sempre a interação entre o indivíduo e a natureza.

\section{Resultados e discussões}

Esse projeto teve início no ano de 2014 e já foi implantado em 23 unidades escolares. O projeto envolveu até a presente data aproximadamente 281 turmas, 7316 alunos e 979 funcionários. Foram instaladas cerca de 820 lixeiras e distribuiu-se mais de 24.885 informativos e implantou-se 16 hortas.

Segundo Oliveira et al. (2009) a questão ambiental requer novas formas de abordagem, integrando as várias áreas de conhecimentos e tendo como foco principal o despertar da consciência, principalmente das crianças e dos adolescentes, para que assim novos hábitos possam ser formados, direcionando a espécie humana a utilizar os recursos naturais de forma sustentável. $E$ esses novos hábitos foram percebidos por meio da mudança comportamental dos alunos e funcionários nas suas relações com o ambiente escolar, que ocorreu principalmente na diminuição da quantidade de resíduos gerados, no menor desperdício de alimentos nas refeições e no aumento do material encaminhado para reciclagem. Percebeu-se durante o monitoramento do projeto um maior conhecimento e consciência dos envolvidos sobre as questões ambientais, percepção essa evidenciada principalmente durante as atividades de Educação Ambiental desenvolvidas mostrando que, segundo Cornelius et al. (2011), a EA não se restringe ao ambiente escolar, porém este é um contexto privilegiado para a formação de opinião, que se torna mais forte quando há plena participação dos pais e da comunidade em geral, como podese perceber neste projeto.

Assim, segundo Santos e Gardolinski (2016) a implantação da Educação Ambiental nas escolas pode ser considerada uma das formas mais eficazes para a conquista de uma sociedade sustentável, desenvolvendo o senso crítico, a mudança de comportamento, incentivando o respeito à vida e disseminando novas práticas de uso dos recursos naturais. 


\section{Considerações finais}

A Educação Ambiental é um dos principais caminhos para a difusão de conhecimentos e práticas sustentáveis, mas para que a mesma chegue ao seu objetivo de tornar o planeta melhor, os educadores precisam de forma criativa descobrir as melhores formas (pedagógicas, técnicas, tecnológicas, etc.) de se fazer EA, sempre seguindo o princípio que é com o conhecimento que se alcança a real mudança de hábitos e que todos podem contribuir, mesmo com pequenas ações, para uma casa, uma escola, um bairro, uma cidade, um país e um planeta melhor.

\section{Referências}

CAVALCANTI, C. Meio ambiente, desenvolvimento sustentável e políticas públicas. 4. ed. São Paulo: Cortez: Recife/Pe: Fundação Joaquim Nabuco. 2002. 436p.

CONAE/PR. Educação, trabalho e desenvolvimento sustentável: cultura, ciência, tecnologia, saúde, meio ambiente. Livro 3: reflexões e provocações/Monica Ribeiro da Silva (organizadora). 1. ed. Curitiba: Appris, 2015. 109p.

CORNELIUS, F.; MORIGGI, E.M.; REMPEL, C.; MARTINS, S.N. Projetos de Educação Ambiental na Escola: desenvolvendo a consciência ambiental. Caderno pedagógico, Lajeado, v. 8, n. 2, p. 57-66, 2011. Disponível em: $<$ http://www.univates.br/revistas/index.php/cadped/article/view/835>. Acesso em: 09 ago. 2019.

OLIVEIRA, M. S. J. L. et al. Meio ambiente e Educação Ambiental na percepção de professores de ensino fundamental e médio. BioFar Revista de Biologia e Farmácia, v.3, n.1, p. 88-104, 2009.

SANTOS, S. P. S.; GARDOLINSKI, M. T. H. A. A Importância da Educação Ambiental nas Escolas para a Construção de uma Sociedade Sustentável. 2016.

$<$ http://www2.al.rs.gov.br/biblioteca/LinkClick.aspx?fileticket=1 VmNggPU170\%3 D\&tabid $=5639$ > . Acesso em: 08 set. 2019.

SMYTH, J. C. Environmental education: a view of a changing scene. In Environmental Education Research, v.1, n.1, 1995. 